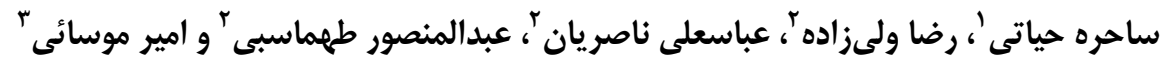

ا و r- دانش آموختهى كارشناسى ارشد و استاد، كروه علوم دامى، دانشخاه فردوسى مشهرد

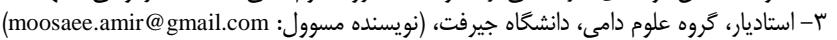
تاريخ بذيرش: ت

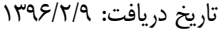

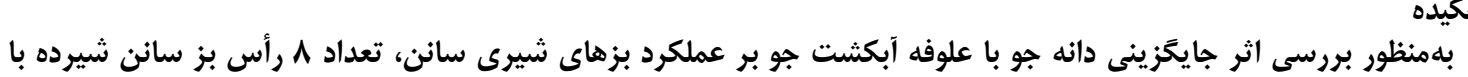

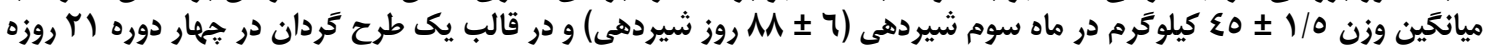

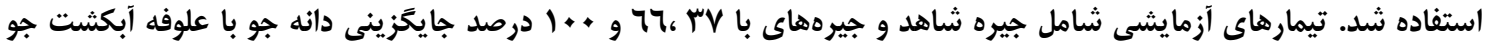

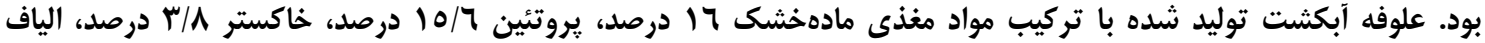

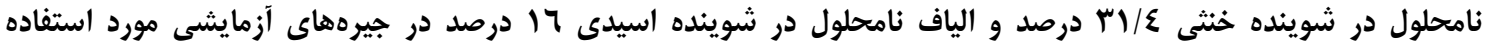

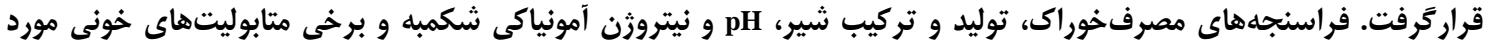

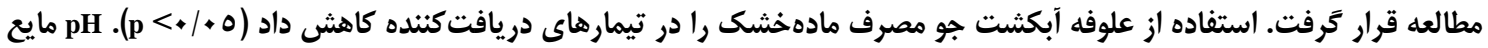

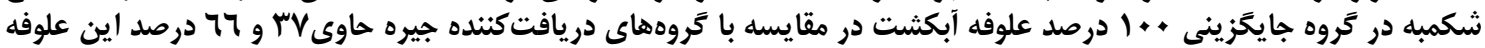

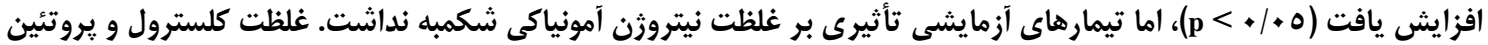

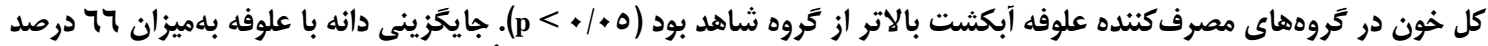

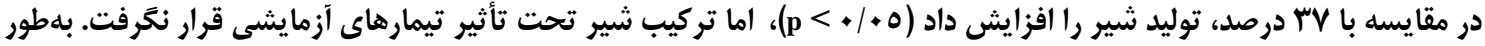

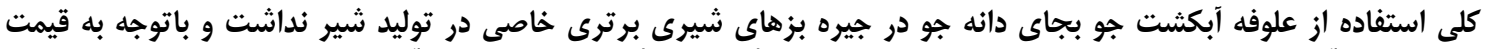

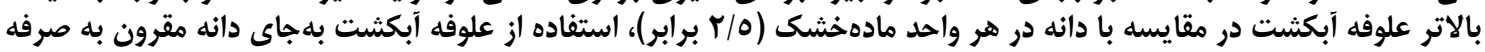

وازههاى كليدى: براورد اقتصادى، بز سانن، توليد شير، علوفه آبكثت جو

ساختارى ديواره سلولى، كه بر pH شكمبه و توليد تربى شير

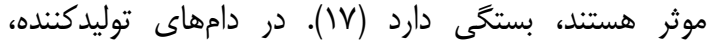

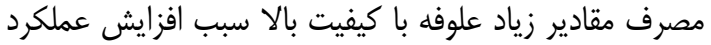
و سوددهى اقتصادى مى شود.

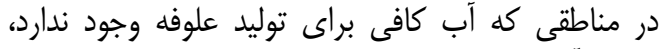

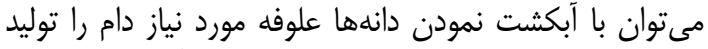

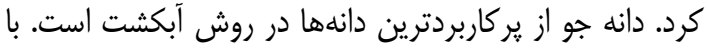

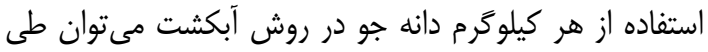

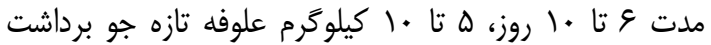

نمود (9).

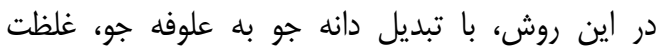

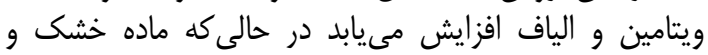

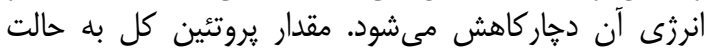

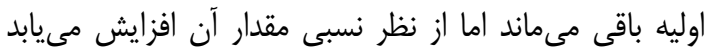

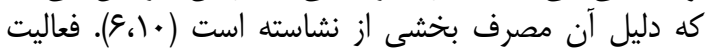

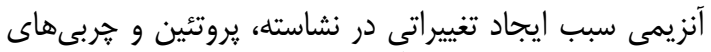

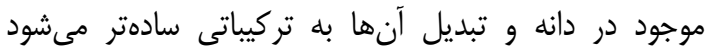

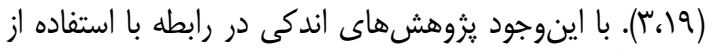

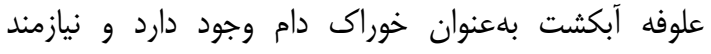

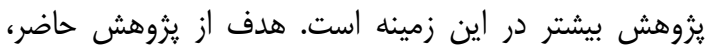

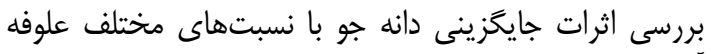

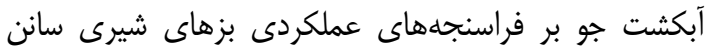

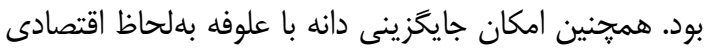

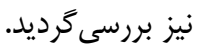

شاخصهاى بحران آب در كشور ايران بهعلت قرار كرفتن

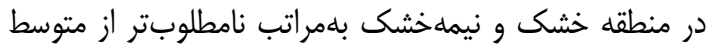

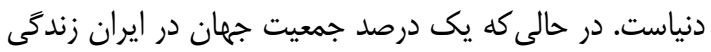

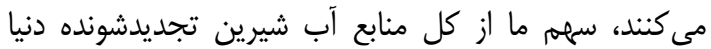

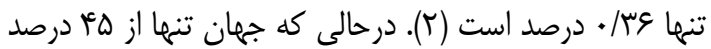

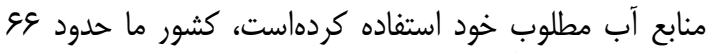

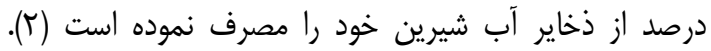

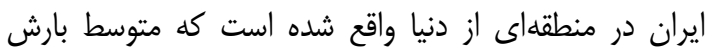

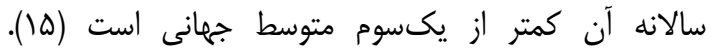

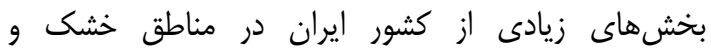

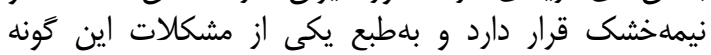

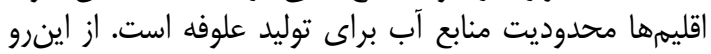

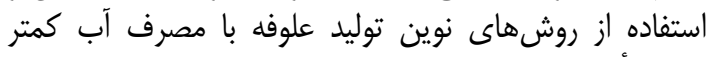

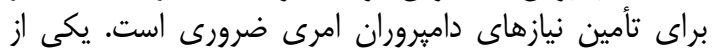

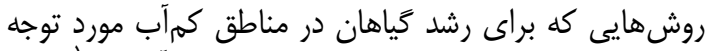

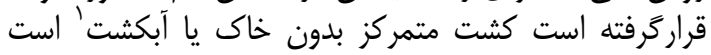

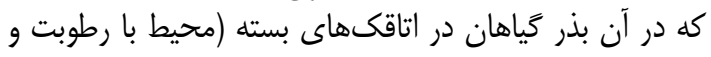

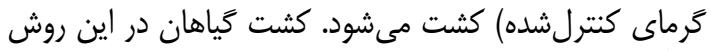

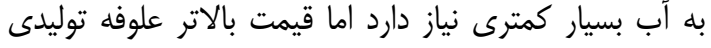

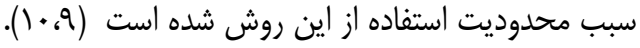

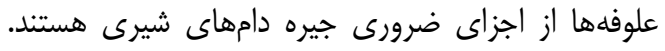

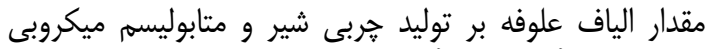

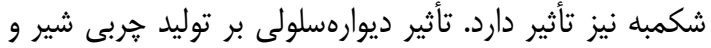

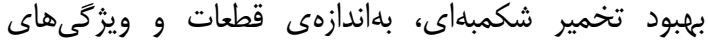


دستخاه شيردوش و دو بار در روز (صبح و عصر) انجام شد.

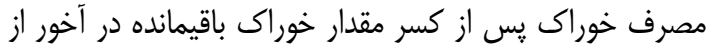

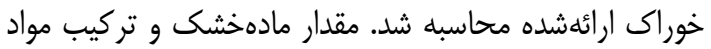

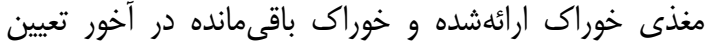

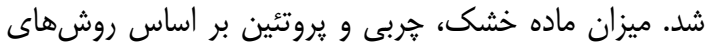
AOAC

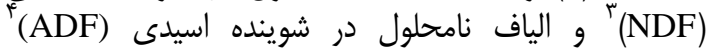

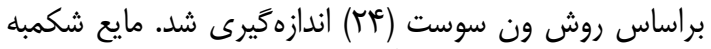

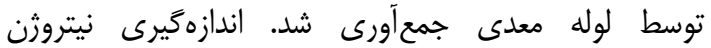

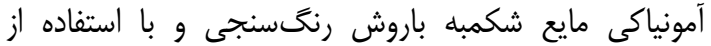

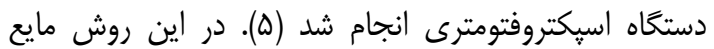

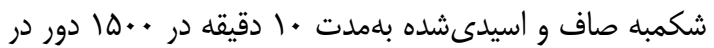

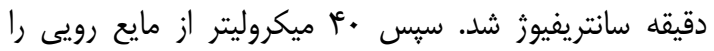

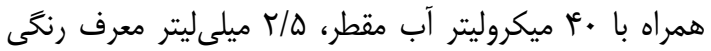

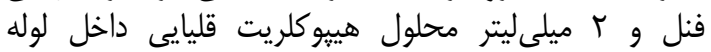

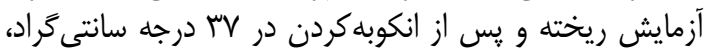

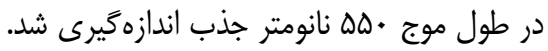

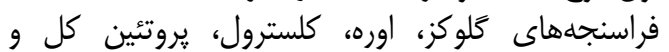

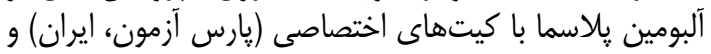

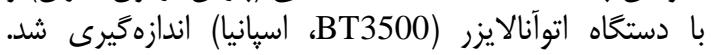

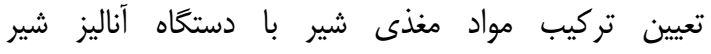

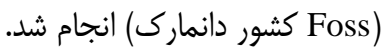

مواد و روشها

اين آزمايش در ايستخاه يزوهشى دام و طيور دانشكده

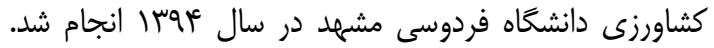

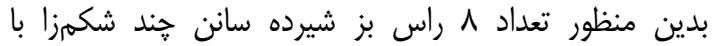

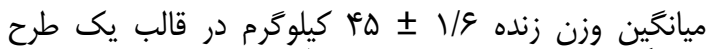

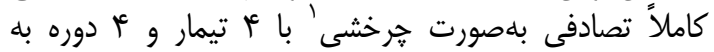

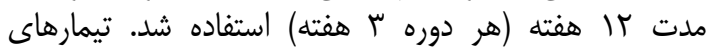
آزمايش شامل (1) عدم جايكزينى دانئ دانه جو با با علوفه آبكشت

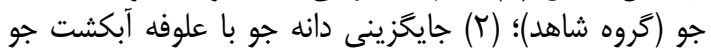

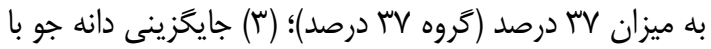

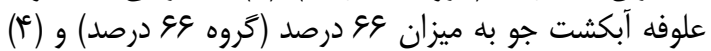

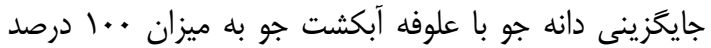

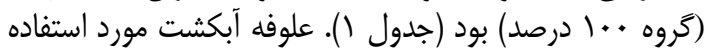

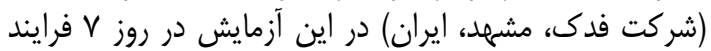

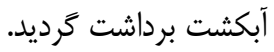

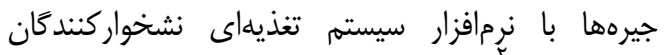

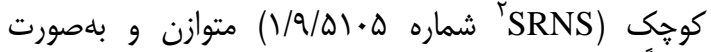

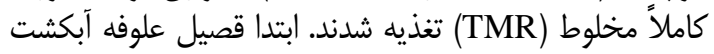

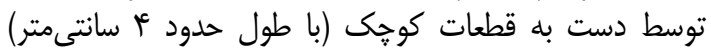

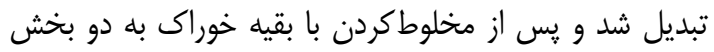

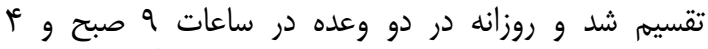
بعدازظهر در اختيار دامها قرار كَرفت. در هفته آخر هر دورئه

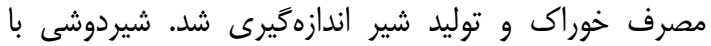

جدول 1- مواد خوراكى و تركيب مواد مغذى جيرههاى آزمايشى (براساس درصد ماده خشك) Table 1. Ingredients and feed composition of experimental diets (based on DM percent)

\begin{tabular}{|c|c|c|c|c|}
\hline \multicolumn{4}{|c|}{ كروه أزمايشى } & \multirow{2}{*}{ ماده خوراكى (درصد) } \\
\hline 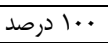 & |999 درصد & 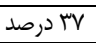 & شاهد & \\
\hline 10 & 10 & 10 & 10 & يونجه خشك \\
\hline r. & r. & r. & r. & علوفه ذرت سيلوشده \\
\hline - & 9 & 11 & tr & دانه جو \\
\hline tr & 11 & 9 & - & علوفه سبز جو \\
\hline r & $\Gamma / \Delta$ & $r / \Delta$ & $\Delta$ & كنجاله سويا \\
\hline r & r & r & r & يودر كوشت \\
\hline r) & $r \cdot 10$ & $19 / \Delta$ & 19 & سبوس كندم \\
\hline$\cdot / 4$ & $\cdot / 4$ & $\cdot / \kappa^{c}$ &.$/ 4$ & كربنات كلسيم \\
\hline.$/ 4$ &.$/ 4$ &.$/ 4$ &.$/ 4$ & مكمل مواد معدنى - ويتامينى' \\
\hline.$/ 4$ & $\cdot / \pi$ & $\cdot / \pi$ &.$/ 4$ & نمكى \\
\hline \multicolumn{5}{|c|}{ تر كيب مواد مغذى (درصد) و انرزى قابل سوخت و ساز } \\
\hline$\Delta r$ & $\Delta V$ & 90 & VT & ماده خشك \\
\hline$r / 90$ & $r / 99$ & $r / V$ & T/VG & انرزى قابل سوخت و ساز (مكاكالرى) \\
\hline $1 Q / \Delta \&$ & $10 / 4 \lambda$ & $1 \% / 4$ & $1 \% / 99$ & بروتئين خام \\
\hline$F T / T^{C}$ & $F T / F$ & $r \cdot / \kappa$ & $r \cdot / \Lambda$ & الياف نامحلول در شويندهى خنثى \\
\hline r) & $r / q$ & $r \cdot / 9$ & $r \cdot / \mathrm{V}$ & الياف نامحلول در شويندهى اسيدى \\
\hline re & Me & צ & ro & كربوهيدرات غيراليافى \\
\hline$r / \Gamma$ & $r / T$ & $r / 1$ & $r / 9$ & عصاره اترى \\
\hline$\cdot / V$ & $\cdot / \mathrm{V}$ & $\cdot / V$ &.$/ 9$ & فسفر \\
\hline.$/ 9$ &.$/ 9$ &.$/ 9$ &.$/ 9$ & كلسيم \\
\hline
\end{tabular}

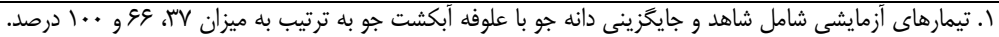

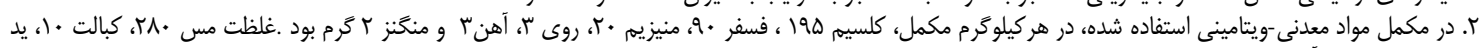

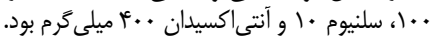

$\mathrm{y}_{\mathrm{ijk} \mathrm{k}}=\mu+\tau_{\mathrm{i}}+\beta_{\mathrm{k}}+\operatorname{SUB}(\beta)_{\mathrm{jk}}+\mathrm{t}_{\mathrm{l}}+\varepsilon_{\mathrm{ijk} \mathrm{l}}$

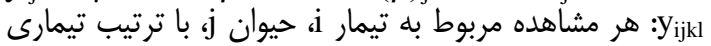

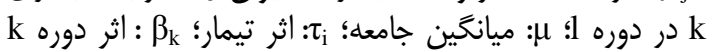

تجزيه آمارى دادهها با رويه Mixed نرمافزار آمارى

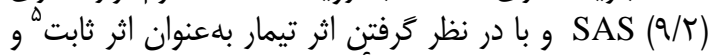

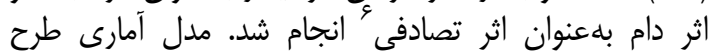
آزمايشى در زير آورده شده است: 
(•) كزارش دادند كه استفاده از علوفه سبز جو توليدشده به جه

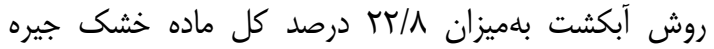

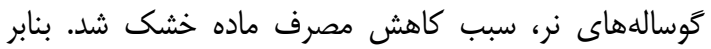

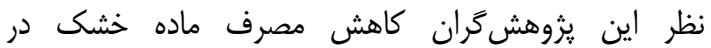

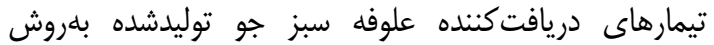

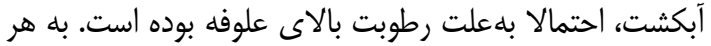

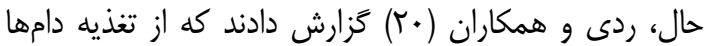

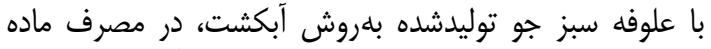

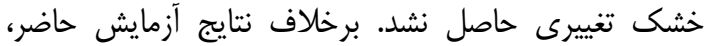

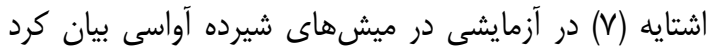

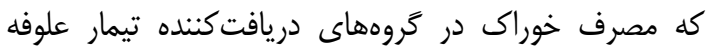

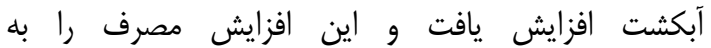

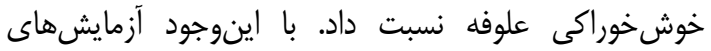

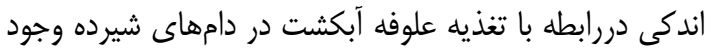

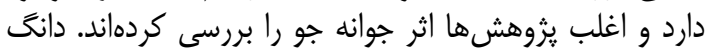

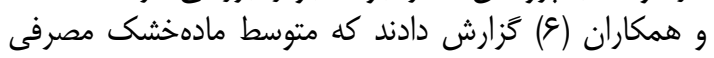

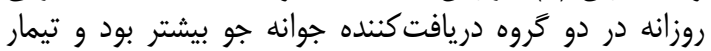

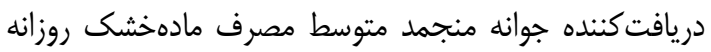

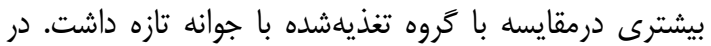

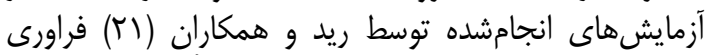

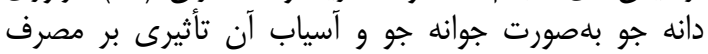

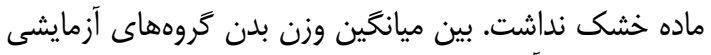

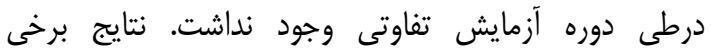

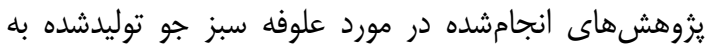

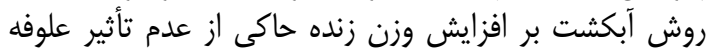

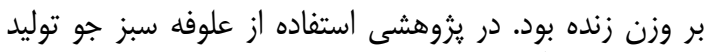

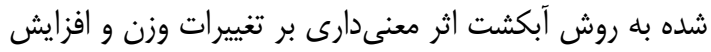
وزن روزانه كاو يروارى نداشت (1)
اعمال تيمار، SUB ( أثر تصادفى حيوان j ز درون دوره

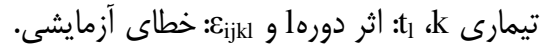

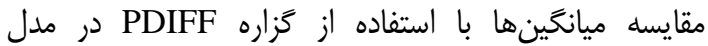

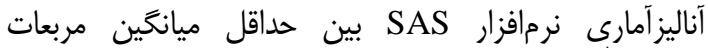

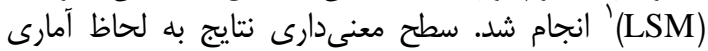

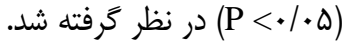

\section{نتايج و بحث تركيب شيميايي علوفه آبكشت جو}

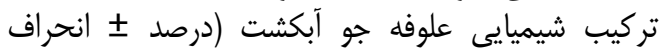

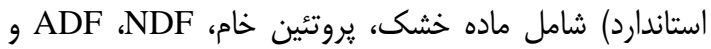

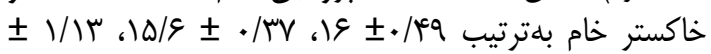

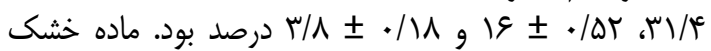

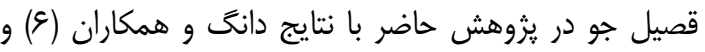

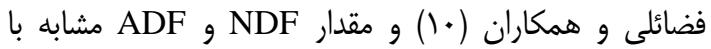

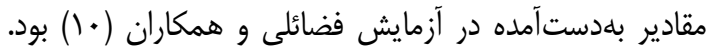

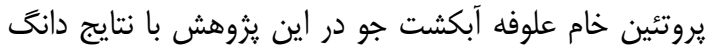

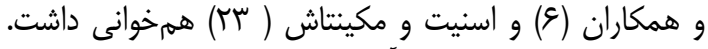

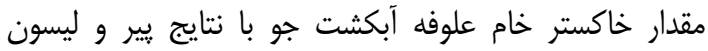

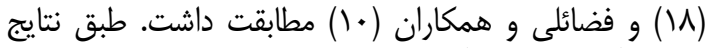

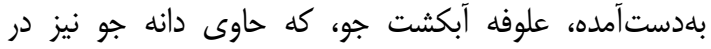

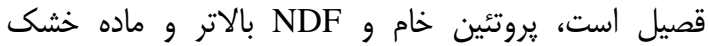
كمترى درمقايسه با دانه جو داشت خامت

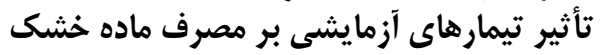

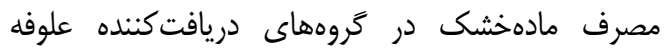

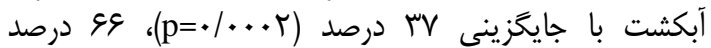

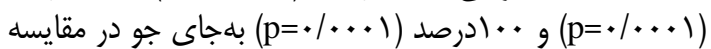
إبا شاهد كاهش يافت. نتايج آزمايش حاضر تا تا حدودى با بانتايج آزمايشات مشابه (•(1) همخوانى داشت. فضائلى و همكاران

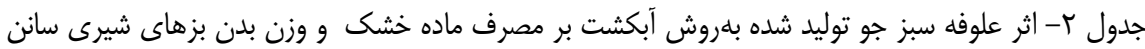
Table 2. Effect of barley hydroponic fodder on dry matter intake and body weight of Saanen lactating goats

\begin{tabular}{|c|c|c|c|c|c|c|c|}
\hline P Value & . & & & & & & \\
\hline درجه دو & 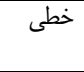 & خطاى استاندارد & ل ب ادرصد & عودرصد & 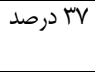 & شاهد & فراسنجه \\
\hline$\cdot|| r \mid$ & $<+\cdots)$ & $1 Q / A \mu$ & $T \cdot r \Lambda^{b}$ & $T \cdot V q^{b}$ & $T \cdot T^{0}$ & $T r \cdot l^{a}$ & مصرف خوراك روزانه (كرم) \\
\hline 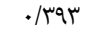 & $\cdot / V \cdot \omega$ & $\cdot$ /Ve & $\mathrm{FV} / \mathrm{G}$ & $\mathrm{FV} / \mathrm{s}^{\mathrm{s}}$ & $\mathrm{rN} /$. & $F V / L^{e}$ & ميانكين وزن بدن (كيلوكرم) \\
\hline
\end{tabular}

كرد كه نيتروثن آمونياكى شكمبه در برههاى دريافت كنينده

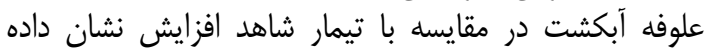

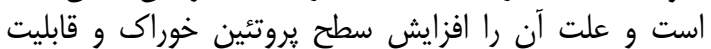

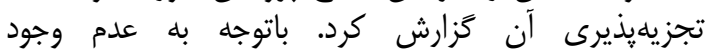

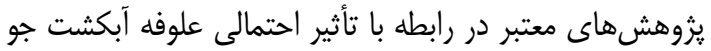

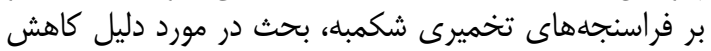

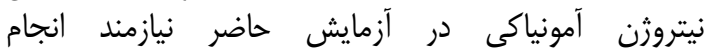
يزوهشهاى بيشتر در اين زمينه است.

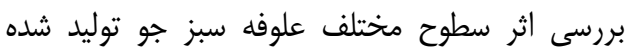
بلهروش آبكشت بر pH مايع شكمبه نشان داد ماد كه تفاوتى بين

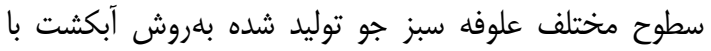

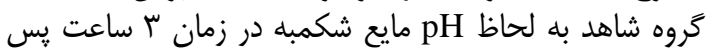

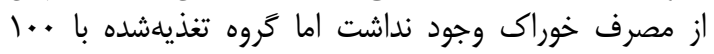

تأثير تيمارهاى آزمايشى بر وضعيت تخميرى شكمبه

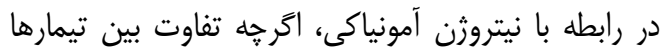

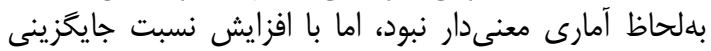

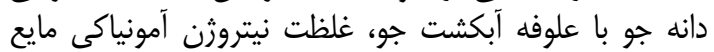

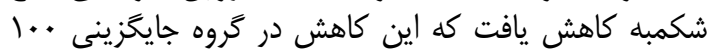

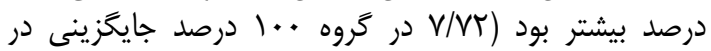

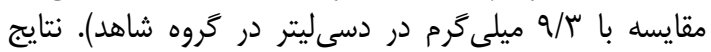

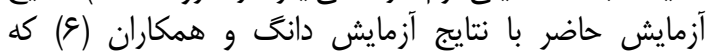

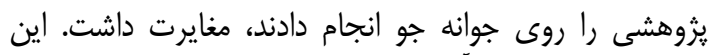

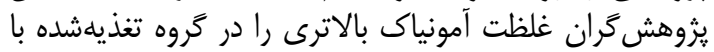

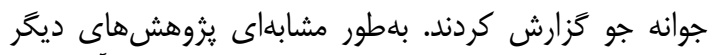

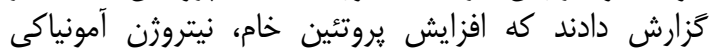

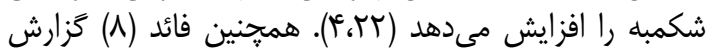


جو و شكستهشدن نشاسته آنها در علوفه آبكشت بهاهمراه

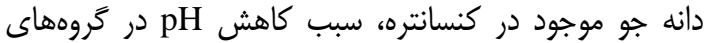

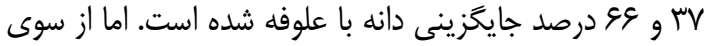

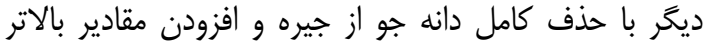

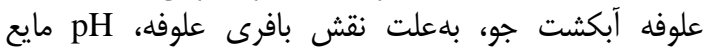
شكمبه افزايش يافته است.

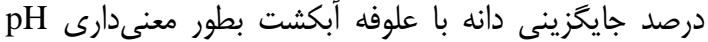

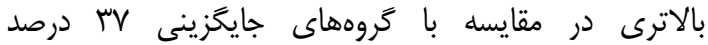

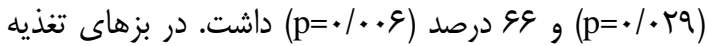

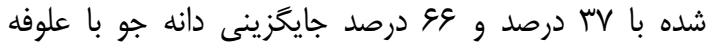

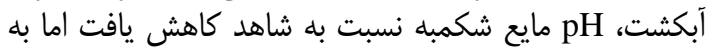
لحاظ آمارى معنى دار نبود. احتمالا، وجود مقادير زياد دانههاى نافي

جدول س- تأثير تيمارهاى آزمايشى برpH و نيتروزن آمونياكى شكمبه بزهاى شيرى سانن Table 3. Effect of experimental treatments on rumen pH and ammonia nitrogen of Saanen lactating goats

\begin{tabular}{|c|c|c|c|c|c|c|c|}
\hline \multicolumn{2}{|c|}{ P Value } & \multirow[b]{2}{*}{ خطاى استاندارد } & \multicolumn{4}{|c|}{ كروه أزمايشى' } & \multirow[b]{2}{*}{ فراسنجه } \\
\hline درجه دو & خطى & & •."ادرصد & وعدرصد & Vآدرصد & شاهد & \\
\hline.$/ . \varphi^{q}$ & $\cdot / \Gamma \Delta$. & $\cdot / \cdot \Delta \Delta$ & $9 / 9 \cdot{ }^{a}$ & $g / \mu^{c b}$ & $9 / 4^{\circ}{ }^{\circ}$ & $8 / 4 q^{a b 0}$ & $\mathrm{pH}$ \\
\hline ./QAr & $\cdot|| \Delta \mid$ &.$/ 911$ & $V / N Y$ & $V / 19$ & N/91 & $q / r$. & دسيتروثي) آمونياكى (ميلى كرم در \\
\hline
\end{tabular}

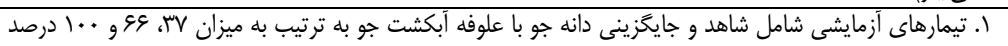

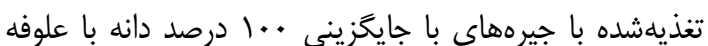

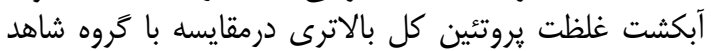

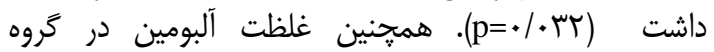

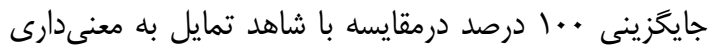

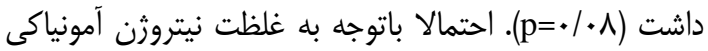

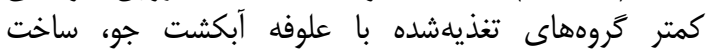

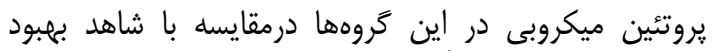

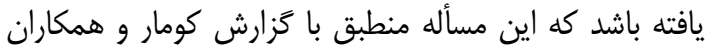

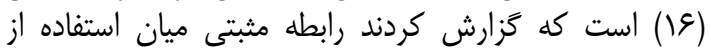

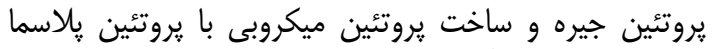

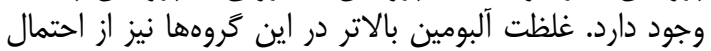

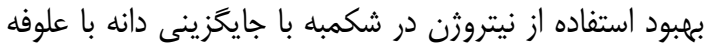
آبكشت جو حمايت مى كند.
فر اسنجههاى خون

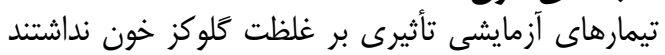

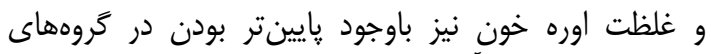

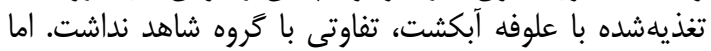

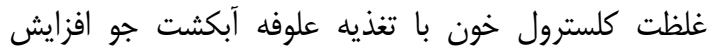

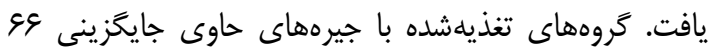

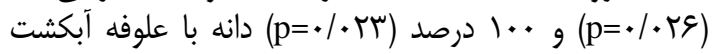

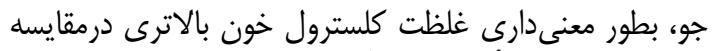

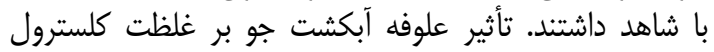

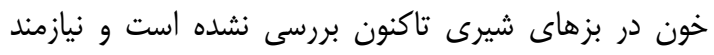

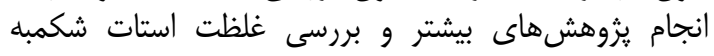

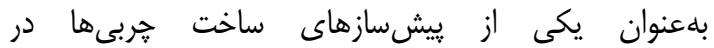

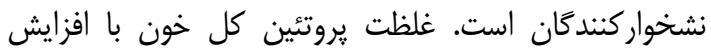

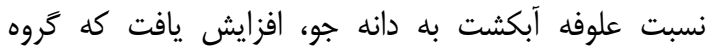
جدول ع- غلظت فراسنجهاى خون بزهاى شيرى سانن

Table 4. Concentration of blood parameters of Saanen lactating goats

\begin{tabular}{|c|c|c|c|c|c|c|c|}
\hline \multicolumn{2}{|c|}{$\mathrm{P}$ Value } & \multirow[b]{2}{*}{ خطاى استاندارد } & \multicolumn{4}{|c|}{ كروه أزمايشى } & \multirow[b]{2}{*}{ فراسنجه } \\
\hline درجه & خطى & & 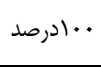 & ع عدرصد & 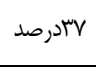 & شاهد & \\
\hline$\cdot / \Delta Q Y$ & $.19 \cdot 9$ & T/Arr & $9 \% / \cdots$ & SV/TV & SY/TV & $9 \Delta / T V$ & كلوكز(ميلى \\
\hline$\cdot / V \cdot \Delta$ & $\cdot / \mathrm{FV}$ & $1 / 19$. & $\Delta r / \cdots$ & $\Delta \Delta / \Delta \cdot$ & $\Delta T / V Q$ & $\Delta N / \Delta$. & وره (ميلى \\
\hline.$/ 991$ & $\cdot 1 \cdot+1$ & 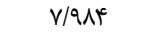 & $1.9 / 9 r^{a}$ & $1.9 / .^{a}$ & $৭ \& / \wedge V^{\mathrm{aD}}$ & $\Lambda) / \mathrm{rV}^{\mathrm{D}}$ & 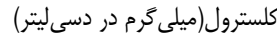 \\
\hline$\cdot / \mathrm{VM}$ & $\cdot 1 \cdot+\Delta$ & $\cdot / \backslash \wedge \Delta$ & $N / \cdot r^{\mathrm{a}}$ & $V / V^{a b}$ & $\mathrm{~V} / \mathrm{VV}^{\mathrm{ad}}$ & $V / F T^{D}$ & بروتئين كل (َرم در دسىليتر) \\
\hline
\end{tabular}

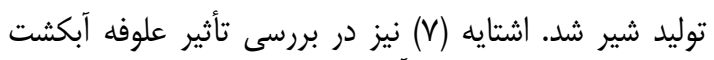

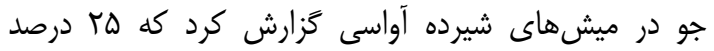

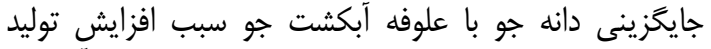

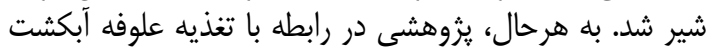

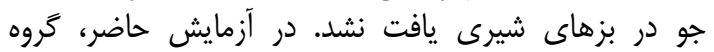
VIسرصد جايگزينى توليد شير كمترى داشت اما گروههاى

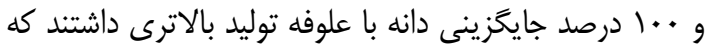

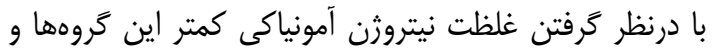

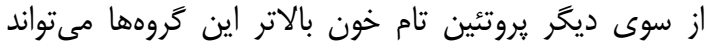

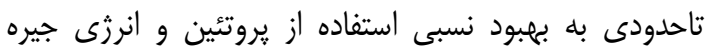
براى توليد شير اشاره كند.

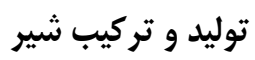

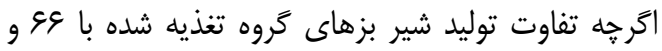

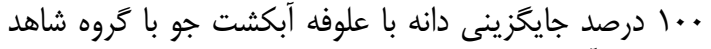

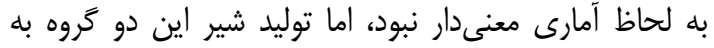

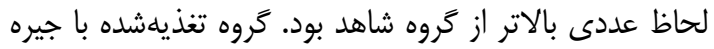

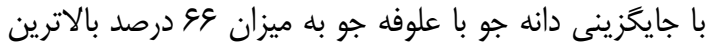

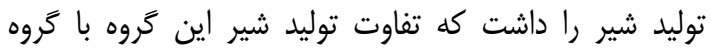

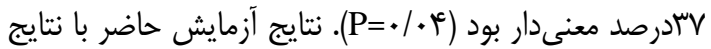

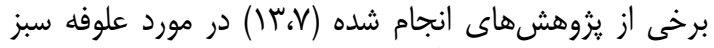

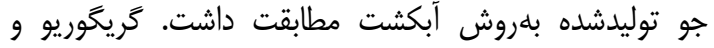

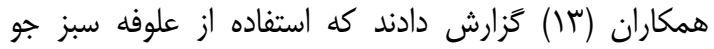

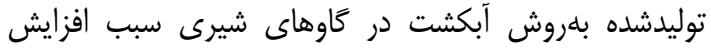


Table 5. Milk production and composition of Saanen lactating goats

جدول ه- توليد و تركيب شير بزهاى شيرى سانن

\begin{tabular}{|c|c|c|c|c|c|c|c|}
\hline \multicolumn{2}{|c|}{ P Value } & \multirow[b]{2}{*}{ خطاى استاندارد } & \multicolumn{4}{|c|}{ كروه أزمايشى } & \multirow[b]{2}{*}{ فراسنجه } \\
\hline 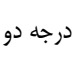 & خطى & & ادرصد & و عدرصد & V V Vادرصد & شاهد & \\
\hline$\cdot / \Delta \cdot V$ &.$/ \cdot \Delta T$ & $r I / q \Lambda$ & $T \& Q)^{\mathrm{ab}}$ & req4a & $r q \cdot 1^{b}$ & TETA & توليد شير روزانه (كَرم) \\
\hline . ATA & $.|| r \mid$ & $.1 .9 \mathrm{~V}$ & $r / \cdot \varphi^{c}$ & $r / \mu$ & $r / \varphi^{c}$ & $r / 90$ & هربى شير (درصد) \\
\hline.$/ 49 V$ &.$/ 114$ & .1 .11 & $r / N E$ & $r / A S$ & r/AV & r/AV & بروتئين شير (درصد) \\
\hline .1990 & .11. & .1 .11 & $\Gamma / \pi \Delta$ & $r / \mu$. & $r / r q$ & $r / r q$ & لاكتوز شير (درصد) \\
\hline.$/ 411$ & $\cdot / 0 \cdot 1$ & 年 & $v / q$. & $V / V^{C}$ & V/AS & V/AT & مواد جامد غيرجربى (درصد) \\
\hline
\end{tabular}

دوره از سال و در طى مدت كوتاهى با توجه به نيازمصرفى در

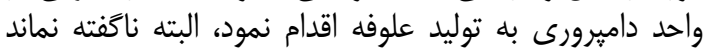

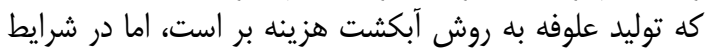

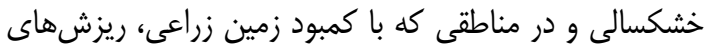

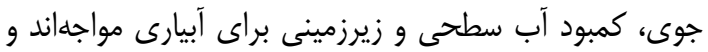

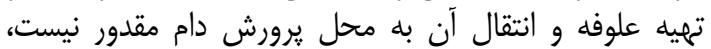

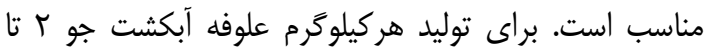

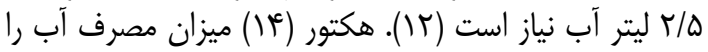

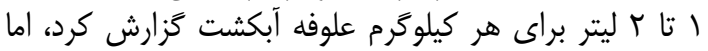

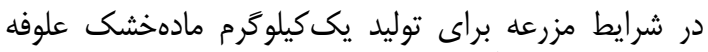

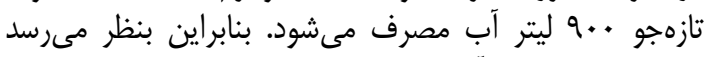

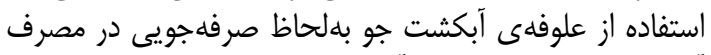

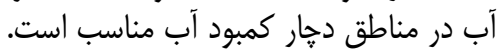

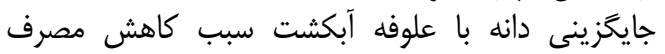

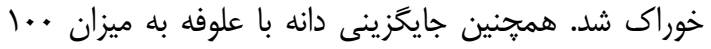

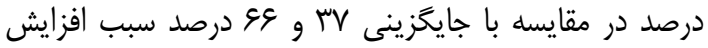

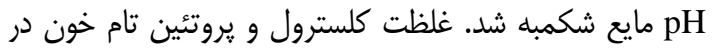

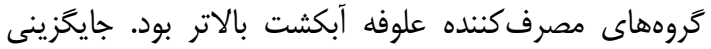

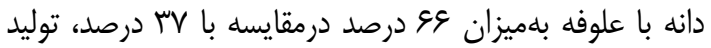

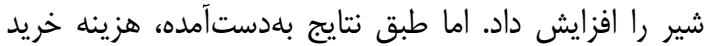

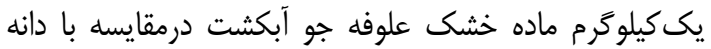

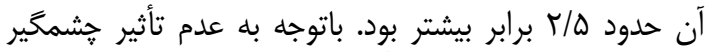

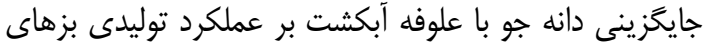

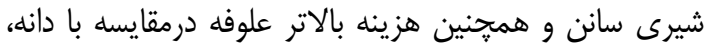

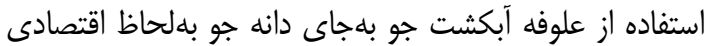

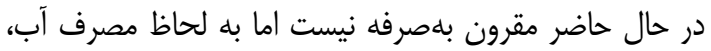

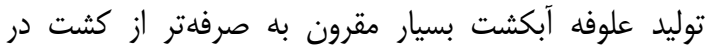

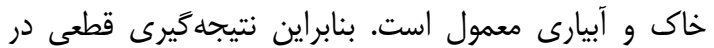

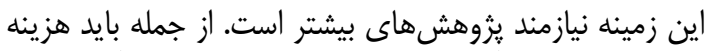

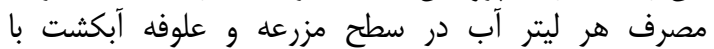
قيمتهاى واقعى درنظر گرفته شود.
غلظت لاكتوز شير در بزهاى تغذيهشده با جيره شاهد

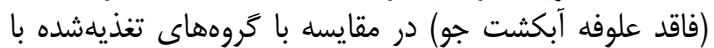

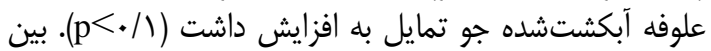

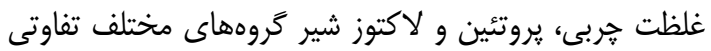

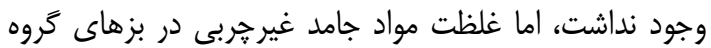

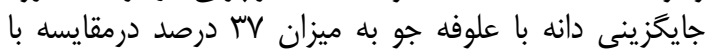

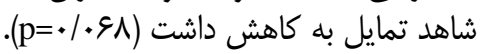

هزينه تمامشده براى خريد بائ علوفه داهن

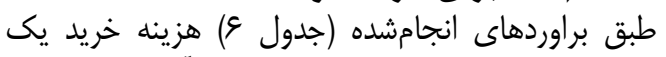

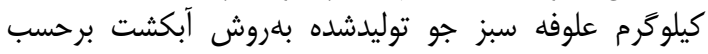

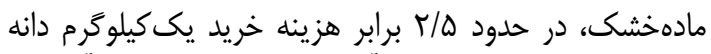
جو است. طبق مشاهدات و آناليزهاى انجام شده درد در در آزمايش

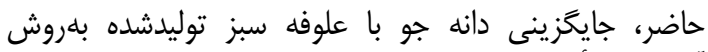

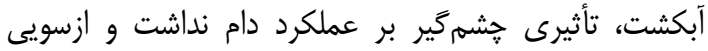

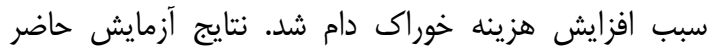

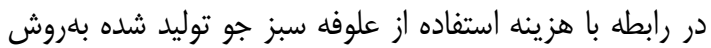

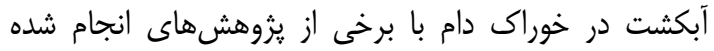

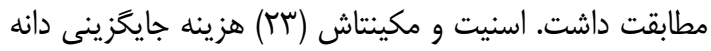

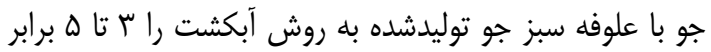
كزارش كردند.

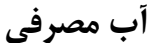

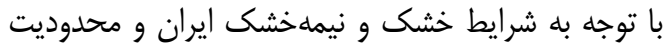

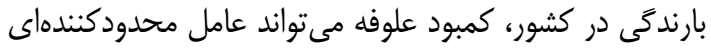

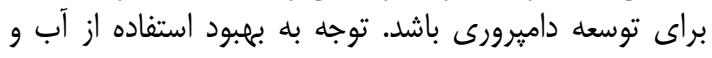

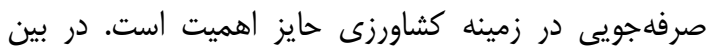

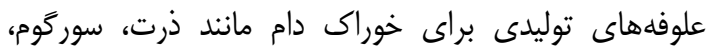

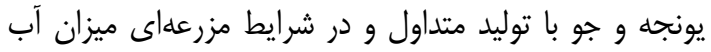

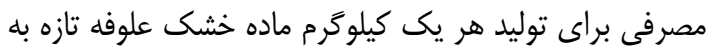

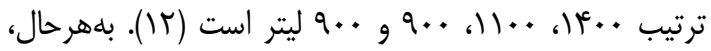

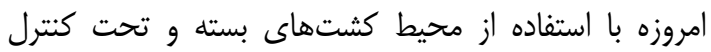
هيدرويونيك مىتوان با استفاده از دانه غلات مذيط مذكور در هر 
Table 6. Cost of buying barley grain and barley hydroponic fodder

جدول و- هزينه خريد دانه جو و علوفه سبز جو توليد شده بلروش آبكشت

\begin{tabular}{|c|c|c|}
\hline علوفه أبكشت جو & دانه جو & فراسنجه \\
\hline$q / T^{c}$ & 1 & وزن تر يا As fed (كيلوگرم) \\
\hline 19 & q. & ماده خشك (درصد) \\
\hline $1 / 2$ &.$/ 9$ & ماده خشك (كيلوگرم) \\
\hline f... & $q \ldots$ & هزينه خريد به ريال (يك كيلوگرم برحسب As fed) \\
\hline rFqa. & $1 \cdots$ & هزينه خريد به ريال (يكى كيلوگرم ماده خشى) \\
\hline
\end{tabular}
Washington, DC. USA.

2. Azadbakht, B. and GH.R. Nourozi. 2008. Geography of waters of Iran. First edition, geographic organization of armed forces. $302 \mathrm{pp}$ (In Persian).

3. Barcelos, M., F.P. de, E.V. Boas, B.V. de and M.A.C. Lima. 2002. Nutritional aspects of combined sprouts of soybean and corn. Ciencia e Agrotecnologia, 26: 817-825.

4. Bohnertd, W., C.S. Schauer, S.J. Falck and T. Delcurto. 2002. Influence of rumen protein degradability and supplementation frequency on steers consuming low- quality forage: II: ruminal fermentation characteristics. Journal of Animal Science, 80: 2978-2988.

5. Chaney, A. L. and E. P. Marback. 1962. Modified reagents for determination of urea and ammonia. Clinical Chemistry, 8:130.

6. Dung, D.D., I.R. Godwin and J.V. Nolan. 2010. Digestive characteristics, ammonia nitrogen and volatile fatty acids levels, in sheep fed oaten chaff supplemented with grimmest barley grain, freezedried or fresh barley sprouts. Journal of Animal and Veterinary Advances, 9: 2493-2501.

7. Eshtayeh, F. A. and J. Abu Omar. 2004. A new source of fresh green feed (hydroponic barley) for Awassi sheep. An-Najah National University. Nablus. Palestine.

8. Fayed, A.M. 2011. Comparative study and feed evaluation of sprouted barley grains on rice straw versus tamarix mannifera on performance of growing Barki lambs. Journal of American Science, 7: 954-961.

9. Fazaeli, H., S. Solaymani and Y. Rouzbahan. 2017. Nutritive value and performance of cereal green fodder yield in hydroponic system. Research on Animal Production, 8 (15).

10. Fazaeli, H., H.A. Golmohammadi, S.N. Tabatabayee and M. Asghari-Tabrizi. 2012. Productivity and nutritive value of barley green fodder yield in hydroponic system. World Applied Sciences Journal, 16 (4): 531-539.

11. Fazaeli, H., H.A. Golmohammadi, A.A. Shoayee, N. Montajebi and S.H. Mosharraf. 2011. Performance of feedlot calves fed hydroponics fodder barley. Journal of Agricultural Science and Technology, 13: 367-375.

12. Golmohammadi, H.A. 2009. The evaluation of productive performance of dairy cows by using hydroponic green fodder. Msc thesis. Islamic Azad University, Khorasgan branch, Isfahan, Iran. (In Persian).

13. Grigorev, N.G., A.L. Fitsev and T.I. Lesnitskaya. 1986. Nutritive value of hydroponics feed and its use for feeding high-yielding cows. Selskokhozyaist Vennaya Biologiya, 7: 47-50.

14. Hector, M. and L. Gallegose. 2004. Hydroponic Green Forage. Identifying Technologies to improve regional Water Stewardship. North Middle Rio Corridor 21-22 April 2004. 84-99.

15. Kardovani, P. 2003. Resources and problems of water in Iran. $6^{\text {th }}$ edition, Tehran university press. Tehran. Iran. $414 \mathrm{pp}$ (In Persian).

16. Kumar, N.U., S. Singh and D.N. Verma. 1980. Effect of different levels of dietary protein and energy on growth of male buffalo calves. Indian Journal of Animal Science, 51: 513.

17. Mertens, D.R. 1997. Creating a system for meeting the fiber requirements of dairy cows. Journal of Dairy Science, 80: 1463-81.

18. Peer, D.J. and S. Leeson. 1985. Nutrient content of hydroponically sprouted barley. Animal Feed Science and Technology, 13: 191-202.

19. Plaza, L., B. De Ancos and M.P. Cano. 2003. Nutritional and health- related compounds in sprouts and seeds of soybean (Glycin max), Wheat, (triticum aestivum 1.) and alfalfa (Medicago sativa) treated by a new drying method. European Food Research Technology, 216: 138-144.

20. Reddy, M.R., D.N. Reddy and V.K.G. Reddy. 1991. Supplementation of barley fodder to paddy straw based rations of lactating crossbred cows. Indian Journal of Animal Nutrition, 8: 274-277.

21. Reed, J.J., M.L. Bauer, E.R. Loe, J.S. Caton and G.P. Lardy. 2005. Effects of processing on feeding value of sprouted barley and sprouted durum wheat in growing and finishing diets for beef cattle. The Professional Animal Scientist, 21: 7-12.

22. Salisbury, M.W., C.R. Krehbiel, T.T. Ross, C.L. Schults and L.L. Melton. 2004. Effects of supplemental protein type on intake, nitrogen balance and site and extent of digestion in white face weathers consuming low-quality grass hay. Journal of Animal Science, 82: 3567-3576.

23. Sneath, R. and F. McIntosh. 2003. Review of hydroponic fodder production for beef cattle. Department of Primary Industries: Queensland Australia 84. McKeehen, pp: 54.

24. Van Soest, P.J., J.B. Robertson and B.A. Lewis. 1991. Methods for dietary fiber, neutral detergent fiber and non-starch polysaccharides in relation to animal nutrition. Journal of Dairy Science, 74: 3583-3597. 


\title{
The Effect of Dietary Barley Grain Substitution with Hydroponic Barley Grass on Milk Yield and Some Blood Metabolites of Saanen Lactating Goats
}

\author{
Sahereh Hayati ${ }^{1}$, Reza Valizadeh ${ }^{2}$, Abbas Ali Naserian ${ }^{2}$, Abdolmansour Tahmasbi ${ }^{2}$ and \\ Amir Moosaee ${ }^{3}$
}

1 and 2- M.Sc. Student and Professor, Department of Animal Science, University of Ferdowsi, Mashhad 3- Assistant Professor, Department of Animal Science, University of Jiroft (Corresponding author: moosaee.amir@gmail.com)

Received: April 29, $2017 \quad$ Accepted: December 16, 2017

\begin{abstract}
An experiment was conducted to evaluate the effects of replacement of barley grain with barley hydroponic fodder on blood metabolites and milk production of lactating Saanen goats. Eight dairy goats $(45 \pm 1.5 \mathrm{~kg}$ of live body weight and 3 months of lactation $(88 \pm 6$ days in milk)) were allocated to 4 experimental diets including the control diet and diets consisting of 37, 66 and 100 percent replacement of barley grain with barley hydroponic fodder, respectively. Animals were assigned to treatments in a cross over design with 4 periods of 21 days each. The barley hydroponic fodder contained $16 \%$ dry matter, $15.6 \%$ crude protein, $3.8 \%$ ash, $31.4 \%$ $\mathrm{NDF}$ and $16 \%$ ADF. Impact of dietary treatments on milk production, rumen and blood parameters were investigated. Feeding barley hydroponic fodder reduced dry matter intake of dairy goats $(\mathrm{P}<0.05)$. The $\mathrm{pH}$ of rumen fluid increased in animals fed diets with $100 \%$ barley fodder in comparison with diet containing 37 and $66 \%$ of barley fodder $(\mathrm{P}<0.05)$, while rumen $\mathrm{NH}_{3}-\mathrm{N}$ was not differed among treatments. Blood cholesterol and total protein concentrations increased in goats fed barley hydroponic fodder $(\mathrm{P}<0.05)$. Animals in $66 \%$ of replacement group produced more milk than $37 \%$ replacement of barley grain with hydroponic fodder $(\mathrm{P}<$ 0.05 ). However, milk composition was not affected by the experimental treatments. The cost of purchasing barley hydroponic fodder was 2.5 times more than barley grain. By considering the effects of barley hydroponic fodder versus grain on performance and higher cost of fodder, it was concluded that using barley hydroponic fodder in replacement of barley grain in the diet of dairy goats is not cost-effective and profitable.
\end{abstract}

Keywords: Barley Hydroponic Fodder, Economical Estimation, Milk Yield, Saanen Goat 